\title{
Design of a System to Implement Occupational Stress Studies Trough Wearables Devices and Assessment Tests ${ }^{\dagger}$
}

\author{
Patricia Concheiro-Moscoso 1,*, María del Carmen Miranda-Duro 1, Carlota Fraga 1, \\ Cristina Queirós ${ }^{2}$, António José Pereira da Silva Marques ${ }^{3}$ and Betania Groba ${ }^{1}$ \\ 1 CITIC, TALIONIS Group, Elviña Campus, Universidade da Coruña (University of A Coruna), \\ 15008 A Coruna, Spain; carmen.miranda@udc.es (M.d.C.M.-D.); fs.carlota.fs@gmail.com (C.F.); \\ b.groba@udc.es (B.G.) \\ 2 Laboratório de Reabilitação, Faculdade de Psicologia e de Ciências da Educação, Universidade do Porto \\ (University of Porto), 4200-374 O Porto, Portugal; cqueiros@fpce.up.pt \\ 3 Laboratório de Reabilitação Psicossocial, Escola Superior de Saúde do Porto, Instituto Politécnico do Porto \\ (Polytechnic of Porto), 4200-374 O Porto, Portugal; antoniomarques@sc.ipp.pt \\ * Correspondence: patricia.concheiro@udc.es \\ + Presented at the 3rd XoveTIC Conference, A Coruña, Spain, 8-9 October 2020. \\ Published: 20 August 2020
}

\begin{abstract}
Introduction: Stress at work is a factor that has repercussions on both a personal and health level, as well as on productivity at work. Objective: To establish if the wearables are devices capable of determining the level of labor stress of working people in a research center. Methodology: This pilot study followed up different variables during 6 months on 11 participants of a research center. In the study, wearables Xiaomi MiB and 3 were used, which recorded and continuously monitored the physical activity and sleep of the participants. On the other hand, different specific evaluation tests were used to measure work stress, quality of life and sleep quality. Results: The data obtained from the tests and the wearables show that men feel slightly more stressed and sleep worse than women; however, men spend more time sitting and walking than women. Conclusions: It is considered important to replicate the study in larger and more heterogeneous cohorts.
\end{abstract}

Keywords: wearables; work stress; quality of life

\section{Introduction}

Work stress is a phenomenon that has been gaining in importance in the recent years. It is defined as "a harmful reaction that people have to cope with the pressures and undue demands placed on them at work" [1]. It has a high impact and repercussions on personal and health levels, as well as on productivity at work [2]. When the occupational stress situation maintenances and increases gradually over time, it could be Burnout [3]. This syndrome is defined as "a prolonged response to chronic emotional and interpersonal stressors at work, and is integrated by the dimensions of burnout, cynicism and inefficiency" [3]. The Burnout has a negative influence in the employment and employees' psychological welfare [4].

Some researches on the stress detection reported to the need for improvements the measurement of daily stressors and in the design of studies with the aim of knowing the influence that the different stress process have in the quality of life [5]. So, in this direction, wearable devices as phones, activity trackers, or sensors could become the main tools for the continuous and real-time monitoring of different parameters in order to contribute to health processes and make a relevant contribution to research [6]. In addition, these technological devices can measure physical activity and sleep quality 
to relate to possible patterns of behavior when exposed to significant stress situations. Some studies, such as Liao et al. (2005), Mozos et al. (2016) and Han et al. (2017), monitored stress in real time through combination of sensors systems to detect stressful situations [7].

This study provides to a new form to capture stress signals by using a smart wristband. Therefore, the aim of this research was to stablish if these wearables are devices capable of determining the level of occupational stress of workers in a research center in Galicia.

\section{Methods}

\subsection{Study Design}

This pilot study was conducted in a research center during 6 months. It included 11 participants based on the inclusion criteria. The inclusion of participants, who were working in an administrative management department from a research center, is highlighted. Prior to participation, informed consent was obtained from all research volunteers. The study protocol was approved by the Autonomic Research Ethics of A Coruña-Ferrol (2019/249).

\subsection{Measures}

\subsubsection{Assessment Tools}

All tools were self-administrated, coded and managed through Consortium Research Electronic Data Capture (REDCAP) software. The tools were designed, configured and assigned to each of participants via REDCAP. Moreover, the researchers followed up on questionnaires that were filled in by the participants during the study.

The sociodemographic questionnaire was self-administrated at the start of the study. Perceived Stress Scale v10, Pittsburgh Sleep Quality Index scale, EuroQol-5D-5L scale were covered at the start and the end of the research.

Weekly questionnaire was composed by 7 questions about stress, work engagement and frustration; 3 questions were daily self-administrated and 4 questions were weekly self-administrated.

\subsubsection{Wearables Devices}

The participants wore Xiaomi Mi Band 3 during 6 months. The activity, sleep and heart rate data were extracted by automatic data acquisition system of TALIONIS group, which was located in the work environment of participants.

\section{Results}

A total of 11 workers participated in this study, who were mostly women $(63.63 \%)$. There were no significant differences between start and final measurements of participants.

The measures associated with health-related quality of life show that some participants reported to slight and moderate problems in the dimensions "pain/discomfort" $(\mathrm{n}=2)$ and anxiety/depression $(n=3)$, specifically at the beginning of the study. In both evaluations, the average score of perceived health status were high $\left(\mathrm{EI}_{\mathrm{I}}=84.56( \pm 8.13) ; \mathrm{EF}=88.38( \pm 9.91)\right)$. PSS-10 results show that the men (Total score $=11.25)$ exhibited higher levels of stress than women (Total score $=9.71)$. This is opposed to weekly questionnaire, which shows that women (total score for women $=15.57$; total score for man = 14.56) had higher level of stress.

Averages scores of PSQI show that participants had slight difficulties to fall asleep and low sleep quality $\left(\mathrm{EI}_{\mathrm{I}}=4.89( \pm 2.62) ; \mathrm{EF}=4.38( \pm 1.85)\right)$. By contrast, wearables reported that participants attained optimal sleep habits. Data from wearables Xiaomi Mi Band 3 show that men were sitting $(7.35 \mathrm{~h})$ and walking $(2.22 \mathrm{~h})$ more time than women $(6.34 \mathrm{~h} ; 1.64 \mathrm{~h})$. However, the women slept for more time $(8.15 \mathrm{~h})$ than men $(7.90 \mathrm{~h})$. 


\section{Discussion and Conclusions}

The aim of this proposal was to establish whether these wearables are devices capable of determining the level of occupational stress of workers. Furthermore, it was determined that the level of occupational stress and quality of life of a group of working people. EQ 5D-5L data show that there were no statically differences associated to sex; this matter is supported by other studies [8]. In general, the participants presented high levels of perceived health status. Men reported more stress than women; in contrast, scientific evidence has reported that the female sex had the highest levels of stress because social, psychological and biological consequences [9]. On the other hand, men showed fewer sleep hours than women; this aspect differs from others studies whose data indicated that women had more sleep problems than men [10]. In conclusion, it is necessary to develop studies with larger sample and with other working environments.

Author Contributions: Conceptualization, methodology, formal analysis and writing P.C.-M., M.C.M.-D., C.F. and B.G.; review, editing, visualization and supervision C.Q., A.J.P.S.M. and B.G.; and funding acquisition, M.C.M.-D. and P.C.-M. All authors have read and agreed to the published version of the manuscript.

Funding: The authors disclosed receipt of the following financial support for the research, authorship, and/or publication of this article: All the economic costs involved in the study will be borne by the research team. This work was supported in part by some grants from the European Social Fund 2014-2020. CITIC (Research Centre of the Galician University System) and the Galician University System (SUG) obtained funds through Regional Development Fund (ERDF) with 80\%, Operational Programme ERDF Galicia 2014-2020 and the remaining 20\% by the Secretaría Xeral de Universidades of the Galician University System (SUG). Specifically, the author PCM obtained a scholarship (Ref.ED481A-2019/069) and the author M.C.M.D. (Ref.ED481A 2018/205) to develop the $\mathrm{PhD}$ thesis. On the other hand, the diffusion and publication of this research was funded by the CITIC, Research Centre of the Galician University System with the support previously mentioned (Ref ED431G2019/01).

Acknowledgments: Financial support from the Xunta de Galicia and the European Union (European Social Fund-ESF), is gratefully acknowledged.

Conflicts of Interest: The authors declare no conflict of interest.

\section{References}

1. Galant-Miecznikowska, M.; Bhui, K.; Stansfeld, S.; Dinos, S.; de Jongh, B. Perceptions of work stress causes and effective interventions in employees working in public, private and non-governmental organisations: a qualitative study. BJPsych Bull. 2016, 40, 318-325.

2. Leka, S.; Griffiths, A.; Cox, T. La organización del trabajo y el estrés. Protección la Salud los Trab. 2004, 3, 137.

3. Maslach, C.; Schaufeli, W.B.; Leiter, M.P. Job Burnout. Annu. Rev. Psychol. 2001, 52, 397-422.

4. Estévez-Mujica, C.P.; Quintane, E. E-mail communication patterns and job burnout. PLoS ONE 2018, 13, e0193966.

5. Neupert, S.D.; Almeida, D.M.; Mroczek, D.K.; Spiro, A. Daily stressors and memory failures in a naturalistic setting: Findings from the VA normative aging study. Psychol. Aging 2006, 21, 424-429.

6. Muaremi, A.; Arnrich, B.; Tröster, G. Towards Measuring Stress with Smartphones and Wearable Devices During Workday and Sleep. Bionanoscience 2013, 3, 172-183.

7. Han, L.; Zhang, Q.; Chen, X.; Zhan, Q.; Yang, T.; Zhao, Z. Detecting work-related stress with a wearable device. Comput. Ind. 2017, 90, 42-49.

8. Xie, F.; Pullenayegum, E.; Gaebel, K.; Bansback, N.; Bryan, S.; Ohinmaa, A.; Poissant, L.; Johnson, J.A. A Time Trade-off-derived Value Set of the EQ-5D-5L for Canada. Med. Care 2016, 54, 98-105. 
9. Nordin, M.; Nordin, S. Psychometric evaluation and normative data of the Swedish version of the 10-item perceived stress scale. Scand. J. Psychol. 2013, 54, 502-507.

10. Uhlig, B.L.; Sand, T.; Ødegård, S.S.; Hagen, K. Prevalence and associated factors of DSM-V insomnia in Norway: The Nord-Trøndelag Health Study (HUNT 3). Sleep Med. 2014, 15, 708-713.

(C) 2020 by the authors. Licensee MDPI, Basel, Switzerland. This article is an open access article distributed under the terms and conditions of the Creative Commons Attribution (CC BY) license (http://creativecommons.org/licenses/by/4.0/). 